\title{
The effect of oestrogen on uterine plasticity in late pregnant rats
}

\author{
S. Ichikawa and H. Tamada \\ Laboratory of Animal Reproduction, College of Agriculture, University of Osaka Prefecture, \\ Sakai City, Osaka, Japan
}

\begin{abstract}
Summary. Intrauterine pressure was recorded in anaesthetized rats on Day 20 of pregnancy by the replacement of a conceptus with a balloon. Intrauterine pressure in ovariectomized pregnant rats treated with progesterone alone was markedly higher than that in intact pregnant rats, but treatment with oestradiol as well reduced values to those of controls. Oestriol and oestrone were less effective. Uterine tolerance, tested by increasing the balloon volume until the uterus ruptured, was greater than $6.5 \mathrm{ml}$ in intact rats and in ovariectomized rats treated with progesterone + oestradiol, but rupture occurred at a volume of $4.3 \mathrm{ml}$ when progesterone alone was used. One of the roles of oestrogen during late pregnancy in rats may be to ensure sufficient plasticity of the uterus to allow for the increase in conceptus size.
\end{abstract}

\section{Introduction}

Haterius (1936), Zeiner (1943) and Alexander \& Frazer (1954) noted distortion or elongation of fetuses in rats ovariectomized in the second half of pregnancy, and stated that it was apparently due to increased intrauterine pressure. The increase in uterine pressure in ovariectomized pregnant rats can be prevented by appropriate treatment with ovarian hormones. This study is designed to examine the effects of progesterone and oestrogen on uterine plasticity in the stage of rapid fetal growth in late pregnancy in rats.

\section{Materials and Methods}

\section{Animals}

Adult virgin, female Sprague-Dawley rats bred in this laboratory were used. They were mated with males at a body weight of $180-220 \mathrm{~g}$. The day when spermatozoa were observed in vaginal smear was designated as Day 1 of pregnancy. Rats were bilaterally ovariectomized on Day 14 of pregnancy and treated daily with $4 \mathrm{mg}$ progesterone alone or with $0.2 \mu \mathrm{g}$ oestrogen per day. The steroids were dissolved in $0.2 \mathrm{ml}$ sesame oil and injected subcutaneously at 16:00 $\mathrm{h}$ each day.

\section{Determination of intrauterine pressure}

Intrauterine pressure was determined in the morning on Day 20 of pregnancy. The abdomen of the rat was opened under ether anaesthesia. The conceptus products of one live fetus were removed through a small incision on the antimesometrial side of the uterine wall about $1-2 \mathrm{~cm}$ distant from the ampulla. An empty balloon was inserted into the ampulla through the incision, and was inflated to a volume of 2.5 or $2.8 \mathrm{ml}$. The balloon was made of a thin latex and connected by polyethylene tubing to a mercury manometer. The balloons used were of a constant size, so that when inflated to the volume of $2.5 \mathrm{ml}$ the pressure within the balloon was 
$20-25 \mathrm{mmHg}$, and when inflated to $2.8 \mathrm{ml}$ the pressure was $27-32 \mathrm{mmHg}$; as long as the pressures within the balloons were in these ranges the balloons were used repeatedly. The pressures within the balloon when it was placed in the uterine ampulla and outside the uterus were determined at a constant volume, and the difference between the two pressures was designated as the intrauterine pressure and expressed in $\mathrm{mmHg}$. The abdomen was covered with a gauze immersed in warm saline during the measurement. Pressure determinations in each ampulla were completed within $1 \mathrm{~min}$. Deep ether anaesthesia was maintained throughout the determinations to keep uteri quiescent.

The tolerance of the uterine wall against inner volume was determined by gradually increasing the volume of water in the intra-ampullary balloon from 2.0 to $6.5 \mathrm{ml}$ at the rate of $0.2 \mathrm{ml} / 10 \mathrm{sec}$. Ampullary borders on both sides of the balloon were tied with sutures to restrict the balloon to the ampulla during inflation. Tolerance was expressed in terms of volume of water in the balloon at the time the uterine wall ruptured.

Immediately after the determination of the intrauterine pressure and tolerance, the animals were killed. The average volume of live fetuses and placentas in each litter was determined by displacement of saline in a graduated cylinder.

\section{Results}

The fetuses, removed for the insertion of a balloon, from rats treated with progesterone alone had to be cut into several pieces for removal because of the tight constriction ring, but fetuses in intact controls and rats treated with progesterone + oestradiol-17 $\beta$ were easily removed without damage. To examine the effect of the transudate from cut fetuses on the intrauterine pressure, several fetuses were cut into pieces before removal in intact and ovariectomized progesterone + oestradiol-treated rats. This procedure had no effect on the pressures recorded and the measurements were combined. The results are presented in Table 1.

Table 1. Effects on Day 20 of progesterone $(P)$ and oestrogen $\left(E_{1}=\right.$ oestrone; $E_{2}=$ oestradiol-17 $\beta$; $\mathrm{E}_{3}=$ oestriol) on intrauterine pressure and uterine tolerance against inner volume in rats ovariectomized (Ovex) on Day 14 of pregnancy

\begin{tabular}{|c|c|c|c|c|c|}
\hline Group & $\begin{array}{l}\text { Treatment } \\
\text { (days) }\end{array}$ & $\begin{array}{l}\text { No. of } \\
\text { rats }\end{array}$ & $\begin{array}{c}\text { Volume of fetus + } \\
\text { placenta (mi) }\end{array}$ & $\begin{array}{l}\text { Intrauterine pressure } \\
\qquad(\mathrm{mmHg})^{*}\end{array}$ & $\begin{array}{l}\text { Uterine tolerance } \\
(\mathrm{ml})\end{array}$ \\
\hline 1 & Intact & 5 & $2.42 \pm 0.09(5)$ & $5 \cdot 5 \pm 0.4(15)$ & $>6 \cdot 5(7)$ \\
\hline 2 & Ovex, P (14-19) & 5 & $2.62 \pm 0.06(5)$ & ${ }^{2} 20.9 \pm 5.2(13)$ & $4.3 \pm 0.2(7)$ \\
\hline 3 & Ovex, $\mathrm{P}, \mathrm{E}_{2}(14-19)$ & 7 & $b_{2} .69 \pm 0.04(7)$ & $5.9 \pm 0.3(21)$ & $>6.5(11)$ \\
\hline 4 & Ovex, $\mathrm{P}, \mathrm{E}_{1}(16,17)$ & 6 & $2.39 \pm 0.10(6)$ & ed $31.3 \pm 5.6(16)$ & - \\
\hline 5 & Ovex, $\mathrm{P}, \mathrm{E}_{2}(16,17)$ & 6 & $\mathrm{~b} 2.67 \pm 0.06(6)$ & $7.0 \pm 0.4(18)$ & - \\
\hline 6 & Ovex, $P, E_{3}(16,17)$ & 6 & $2.42 \pm 0.07(6)$ & ${ }^{c} 18.1 \pm 0.4(18)$ & - \\
\hline
\end{tabular}

Values are mean \pm s.e.m. for the numbers of determinations indicated in parentheses.

Significant differences ( $t$ tests) are indicated: ${ }^{a} P<0.01$ compared to Group $1 ;{ }^{b} P<0.05$ compared to Group 1; ${ }^{c} P<0.01$ compared to Group $5 ;{ }^{d} P<0.05$ compared to Group 6 .

* A balloon volume of $2.5 \mathrm{ml}$ was used in Groups $1-3$ and of $2.8 \mathrm{ml}$ in Groups 4-6.

Intrauterine pressure in rats treated with progesterone alone (Group 2) ranged between 11 and $27 \mathrm{mmHg}$, and the mean value was about 4 times greater than that in intact controls (Group 1). Daily treatment with progesterone + oestradiol (Group 3) maintained the pressure at control levels.

The potency of the three oestrogens tested for the maintenance of lower level intrauterine pressure in ovariectomized, progesterone-treated rats was compared (Groups 4-6). In a preliminary study, treatment with $0.2 \mu \mathrm{g}$ oestradiol-17 $\beta$ on Days 16 and 17 of pregnancy was sufficient for the maintenance of normal pregnancy in ovariectomized, progesterone-treated rats, 
and this daily dose was therefore used for the potency studies. In Groups 1-3, the balloon volume of $2.5 \mathrm{ml}$ was larger than the average volume of fetus and placenta in Group 1, but smaller than the volumes in Groups 2 and 3. However, in Groups 4-6 the pressure was determined at a balloon volume of $2.8 \mathrm{ml}$ which was larger than the volume of fetus and placenta in any group. The results (Table 1) showed that the potency of the oestrogens was in the order of oestradiol $>$ oestriol $>$ oestrone.

In samples from Groups 1-3, the tolerance of the uterine wall to withstand increasing intraampullary balloon volume was determined. Among rats treated with progesterone alone (Group 2) uterine walls ruptured at an average balloon volume of $4.3 \mathrm{ml}$. Uteri in 2 rats treated with progesterone + oestradiol ruptured at a balloon volume of 9.2 and $9.6 \mathrm{ml}$, and uteri in 2 intact controls ruptured at 10.6 and $8.8 \mathrm{ml}$. Since inflation to greater volume reduced the elasticity of the balloons, the inflation was stopped at $6.5 \mathrm{ml}$ thereafter; and in Groups 1 and 3 all uteri examined withstood a volume of up to $6.5 \mathrm{ml}$.

\section{Discussion}

The present study was undertaken to measure the overall tension of the uterine wall in late pregnancy. According to Fuchs (1978), the uterus of the unanaesthetized rat exhibits spontaneous contractions throughout pregnancy, but anaesthesia suppresses the uterine activity and makes the uterus less sensitive to oxytocic agents. Under the present conditions of deep ether anaesthesia uteri were quiescent and no fluctuations were observed in the intrauterine pressure, although the method used for recording was sensitive to small changes in balloon pressure.

Treatment with oestrogen + progesterone prevented the abnormal increases in uterine pressure in progesterone-treated ovariectomized rats, and increased adaptability of the uterine wall to the increasing volume of the intra-ampullary balloon. These results indicate that oestrogen increases the plasticity of the uterus.

As the experimental procedure for the replacement of a conceptus with a balloon is traumatic, it may have stimulated the release of prostaglandins from the uterine tissue. However, there is no evidence that the uterine tissue of ovariectomized rats treated with progesterone alone produces more prostaglandins than that of rats treated with progesterone + oestrogen (Ramwell, Leovey \& Sintetos, 1977). Furthermore, anaesthesia makes the uterus less sensitive to oxytocic agents, as mentioned above. It is, therefore, difficult to consider that prostaglandins and/or other endogenous stimulants are responsible for the higher intrauterine pressure in ovariectomized, progesterone-treated rats.

The mechanism by which oestrogen increases the plasticity of the uterus is not clear. The effects of oestrogen and progesterone on the accumulation in the uterine tissue of collagen and mucopolysaccharides, which are the chief constituents of the ground substance in the endometrial stroma and presumably responsible for the plasticity of the tissue, have been studied biochemically and histologically. Collagen formation in the uterus closely parallels growth in wet weight of the uterus during pregnancy (Harkness \& Harkness, 1954), and the combined treatment of progesterone and oestrogen produces a rapid accumulation of collagen in the uteri of ovariectomized rats (Morgan, 1963; Smith \& Kaltreider, 1963). The administration of progesterone or oestrogen alone had no distinct effect on the collagen content in the whole uterus, but histological studies showed that oestrogen is necessary for the deposition and maintenance of collagenous bundles in the rat endometrium (Fainstat, 1962). Oestrogen also causes accumulation of mucopolysaccharides, which bind to water-soluble proteins and collagen fibres in the ground substance (Zachariae, 1958; Smith \& Henzl, 1969). Thus the accumulation of collagen and mucopolysaccharides, together with increased water uptake after oestrogen treatment, will improve the plasticity of the uterine wall. Oestriol exhibited a higher potency than oestrone for 
increasing the uterine plasticity but the physiological significance of this observation remains to be investigated.

Unlike oestrogen, progesterone is known to block the synthesis of mucopolysaccharides (Smith \& Henzl, 1969) and the lower plasticity of the uterine wall in ovariectomized, progesterone-treated rat may be partly due to this action of progesterone.

The present results suggest that oestrogens improve plasticity of the uterus of the pregnant rat, thereby maintaining proper intrauterine pressure for the growing fetuses in late pregnancy.

\section{References}

Alexander, D.P. \& Frazer, J.F.D. (1954) The effect of spaying in the pregnant rat. J. Physiol., Lond. 124, $36-37 \mathrm{P}$.

Fainstat, T. (1962) Hormonal basis for collagen bundle generation in uterine stroma: extracellular studies of uterus. Endocrinology 71, 878-887.

Fuchs, A.-R. (1978) Hormonal control of myometrial function during pregnancy and parturition. Acta endocr., Copenh. 89, Suppl. 221.

Harkness, M.L.R. \& Harkness R.D. (1954) The collagen content of the reproductive tract of the rat during pregnancy and lactation. J. Physiol., Lond. 123, $492-500$.

Haterius, H.O. (1936) Reduction of litter size and maintenance of pregnancy in the oophorectomized rat: evidence concerning the endocrine role of the placenta. Am. J. Physiol. 114, 399-406.

Morgan, C.F. (1963) A study of estrogenic action on the collagen, hexosamine and nitrogen content of skin, uterus and vagina. Endocrinology 73, 11-19.
Ramwell, P.W., Leovey, E.M.K. \& Sintetos, A.L. (1977) Regulation of the arachidonic acid cascade. Biol. Reprod. 16, 70-87.

Smith, O.W. \& Kaltreider, N.B. (1963) Collagen content of the non-pregnant rat uterus as related to the functional responses to estrogen and progesterone. Endocrinology 73, 619-628.

Smith, R.E. \& Henzl, M.R. (1969) Role of mucopolysaccharides and lysosomal hydrolases in endometrial regression following withdrawal of estradiol and chlormadinone acetate. I. Epithelium and stroma. Endocrinology 85, 50-66.

Zachariae, F. (1958) Autoradiographic $\left({ }^{35} \mathrm{~S}\right)$ and histochemical studies of sulphomucopolysaccharides in the rabbit uterus, oviducts and vagina. Acta endocr., Copenh. 29, 118-134.

Zeiner, F.N. (1943) Studies on maintenance of pregnancy in the white rats. Endocrinology 33, 239249.

Received 26 April 1979 